\title{
Decision-Making Framework for Used Industrial Equipment
}

\author{
Tatjana Karaulova, Viktoria Bashkite
}

\author{
Tallinn University of Technology \\ Ehitajate tee 5, 19086, Tallinn, Estonia \\ E-mail.tatjana.karaulova@ttu.ee; viktoria.bashkite@gmail.ee
}

cross $^{\text {ref }}$ http://dx.doi.org/10.5755/j01.ee.27.1.8618

\begin{abstract}
Decision-making is a major problem in industry. Therefore this research is focused on the decision-making framework development with Lean and Green Manufacturing tools and End-of-Life scenario consideration. A specific mechanism was developed for used industrial equipment life cycle extension in order to save money, nature, and society.

The proposed framework makes business more profitable by including an innovative approach of using complex TRIZ to make it more universal and easy to use for the largest variation of used industrial products. To achieve this aim the Green Matrix was elaborated on the basis of the TRIZ Contradiction Matrix and Green Engineering principles. Much attention was paid to the remanufacturing process in the decision-making framework to assess the moment condition of equipment. An integrated method for evaluating the remanufacturability of the used industrial equipment is proposed, in which the technological, economic and environmental assessment of spent industrial products is analyzed in terms of remanufacturing. Development of an approach for used industrial product assessment improves company inventory controllability and utilization that in turn minimizes environmental impact and resource consumption during the entire product cycle.
\end{abstract}

Keywords: Green Manufacturing (GM), Used Equipment, Life Cycle Analysis (LCA), End-of-Life (EOL) Strategy, Theory of Inventive Problem Solving (TRIZ), Green Matrix, Overall Equipment Effectiveness (OEE).

\section{Introduction}

Modern trends in the manufacturing world are seeking innovative solutions and non-standard approaches to achieve also environmental benefits. Conventional and commonly used manufacturing tools cannot take control over environmental impact. According to EPA, "Lean manufacturing paradigm helps enterprises to systematically eliminate different types of wastes (Peter Paul Electronics, 2013). Nonetheless lean manufacturing philosophy is not covering environmental issues as it is needed today. Implementing practices created to prevent environmental catastrophes and minimize usage of finite resources is not only the $21^{\text {st }}$ century main intention, but also a good opportunity to earn money, because it can decrease the cost and improve the design of used equipment during the remanufacturing phase. More and more companies focus on lean strategies to help them operate in ways that are environmentally responsible (AME, 2007).

The EU Framework Programme for Research and Innovation 2014-2020 will spend around $40 \%$ of its budget for developing "Grand Challenges" project including health and climate change. Horizon 2020 provides a major simplification through a single set of rules. Simplified programme structure and reimbursement model will end bureaucracy that deterred industry from taking part in previous R\&D activities (ES, 2013).

What is Green Manufacturing (GM)? There is no exact definition of this new direction in manufacturing community. Green manufacturing covers the whole life cycle of product from product design (GD), manufacturing, maintenance, and to final discarding (Cheng Wu, 2007). Nevertheless, there is no "recipe" how to be "green". Every entrepreneur has to find a certain way in order to implement the GM concept at a manufacturing process. Elaboration of green methodologies is a very important step toward sustainable manufacturing development, which must be socially equitable, economically viable, and environmentally sound.

There is a certain problem with decision-making process concerning used industrial equipment utilization, new equipment acquisition and various EOL strategies implementation for the old one in SME. It is very complicated to make correct decision in short period of time with limited qualified personnel. Such general approaches as Lean Six Sigma DMAIC, Deming's PDCA and etc. are too general in order to get fast answers to the important questions.

This research is aimed to develop an approach towards a maximum utilization of existing industrial equipment resources at production facility within different manufacturing enterprises. The objective of the current research is green framework development for the assessment and extension of industrial equipment life cycle. The developed approach must ensure analysis of industrial equipment in the EOL stage and facilitate finding of a right decision for its utilization through the innovative solutions in order to increase the economic and ecological benefits in the shortest time possible.

What it gives:

- GM projects' integration into the enterprise's daily life makes business more sustainable and efficient by saving natural resources for future generations and through used equipment the life cycle extension.

- Development of an assessment tool for used industrial products improves company's inventory controllability and utilization that in turn minimizes 
environmental impact and resource consumption during the entire product cycle.

- New challenges and tasks encourage engineers to find innovative and non-standard solutions, which helps to create new positions in the manufacturing sector.

\section{EOL Strategies for Industrial Equipment}

The development strategy of eco-industrial as a basis of circular economy is moving towards closing processing and manufacturing loops in industrial systems. In order to meet the same targets for used industrial equipment, the closed loops can be achieved by implementing two ways. One approach is the realization of different EOL strategies in individual case studies what can show benefit specifically for that unit (Moseichuk et al., 2010; Karaulova et al., 2012). Another is the reverse logistics concept combined with EOL strategies that can be seen in the industry (Zahharov et al., 2011; Shevtshenko et al., 2012). According to the most recent findings reviewed in these papers, the best EOL strategy for industrial equipment to prolong its life cycle is a corporation of takeback approach with the remanufacturing concept. This method is widely used in industries all over the world. Combination of remanufacturing end-of-life strategy and take-back approach can save up to 40-60\% of the spending in comparison with absolutely new item production by putting about $20 \%$ of the effort. It has been reported by many researches (Cohen, 1988; Toensmeier, 1992; Wilder, 1988; Lund, 1984). The target in this research is to develop an internal tool for EOL strategy validation without implementing a take-back approach.

Very important research was conducted by Brazilian researchers (Saavedra et al., 2013) the exact definitions of EOL scenarios with references to the experts in this area are presented in Table 1.

Table 1

End of Life strategies (EOL)

\begin{tabular}{|c|l|}
\hline EOL & \multicolumn{1}{|c|}{ Main characteristics } \\
\hline Reuse & $\begin{array}{l}\text { Products are used more than once. There is no } \\
\text { preventative repair done and possible problems after its } \\
\text { first life can be obtained. Reuse has no influence on } \\
\text { product's quality, anyway it is not new. }\end{array}$ \\
\hline Repair & $\begin{array}{l}\text { Products' out-of-order parts are replaced and the } \\
\text { functionality is recovered. The quality level of the new } \\
\text { components is high, the whole item has extended the life } \\
\text { cycle. }\end{array}$ \\
\hline Refurbishment & $\begin{array}{l}\text { Product major components are rebuilt to a working state. } \\
\text { Recondition quality level is intermediate and the life extension } \\
\text { level is high. During this procedure there is no item } \\
\text { upgrade to the latest functionality or technology. }\end{array}$ \\
\hline Recycle & $\begin{array}{l}\text { Recycle is the friendlier option from environmental } \\
\text { impact point of view. However, the high energy, time } \\
\text { and material consuming procedure among other options. }\end{array}$ \\
\hline Cannibalization & $\begin{array}{l}\text { "Recovering the used parts of products and quality } \\
\text { depends on the EOL strategies that will be used". }\end{array}$ \\
\hline Remanufacture & $\begin{array}{l}\text { Remanufactured item has the same performance and } \\
\text { quality level what is returned during this procedure with } \\
\text { an accordance to the OEM's specification of the same } \\
\text { new product. }\end{array}$ \\
\hline
\end{tabular}

It is becoming more common that original equipment manufacturers (OEM) are financially and organizationally responsible for the take-back of their products when they reach the end of their life cycle (Ravipudi \&Padmanabhan, 2010). But most manufacturing companies, especially SMEs, are not responsible for take-back as they do not implement any EOL strategies; they do not establish takeback relations because of extra costs, comparatively small production volumes and unpredictable demand resulting in an inefficient reverse product flow. The aim of all the EOL strategies described above is to reduce the ecological and to decrease the total amount of waste. These strategies can be classified according a specific ecological hierarchy of EOL strategies by Lansink and developed by Kamer (Lansink, 1980), as follows from Figure 1.

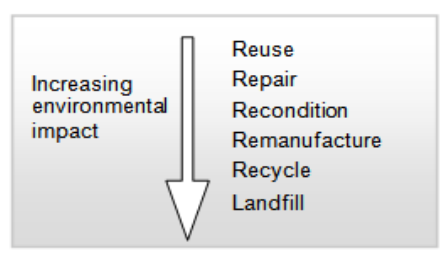

Figure 1. Ecological hierarchy of EOL options

\section{Remanufacturability Assessment Method}

The method for evaluating the remanufacturability of spent industrial equipment is improved and adapted from Chinese researchers (Du et al., 2012) evaluation method for used machine tools.

The idea is to take into consideration three main factors: technological, economic and of course, environmental for spent industrial equipment remanufacturability benefits assessment. The economic issue is rated from the LCC perspective, the aspect of remanufacturing cost and comparison with an analogue of new equipment. This part was adapted and improved by involving the Heinz calculation model (Bloch, 1998) and risk analysis to obtain more precise results. The environmental benefits of used equipment remanufacturing are assessed in terms of energy and material saving. LCC is calculated according to (Bryant et al., 2005) and (Standard, 1996).

The main idea of general approach adapted and upgraded from Chinese researchers' work is shown in Figure 2.

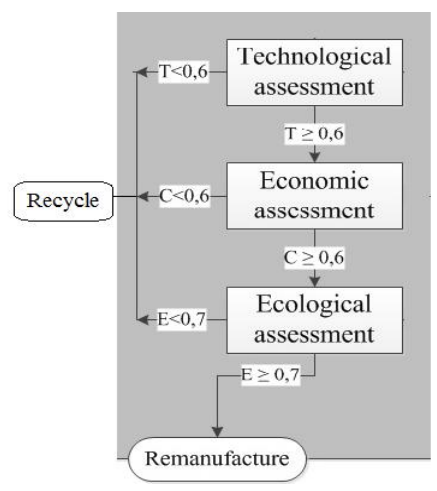

Figure 2. Assessment process for remanufacturability of used machine tools

This approach involves a high proportion of expert judgment. It can influence the final results with an inaccurate outcome. 


\section{Basic Concepts of the Research}

The main decision-making framework of the research is shown in Figure 3. It is divided into three stages: "Equipment state definition" ("Calculate"), "Remanufacturing advisability" ("Analyze") and "Innovative solution search" ("Innovate"). The second part must be used if the right solution could not be found in the first part or as an alternative solution.

The first part is mostly considered as a Lean tool, such as OEE, and equipment age. The age of used industrial equipment is taken into account as the primary criterion of the Calculate part. This will give the needed separation between the cases. Definitely, the first measured criterion is actually OEE (Godfrey, 2002).

The second consists of a mathematical module for remanufacturability assessment with the AHP theory
(Saaty, 2008), the Heinz calculation module and the implementation of the concordance correlation coefficient for more precise expert judgment (Legendre, 2010). It assesses the used product condition from the technology, economy, and ecology perspective. This approach was adapted from Chinese researchers (Du et al., 2012), and developed the integrated method for evaluating the remanufacturability of used machine tools. Estimation of time and costs related to technical realization (Loun et al., 2013) and lean production development (Tahemaa et al., 2012).

The third stage is dedicated to innovative solution finding by the introduction of various TRIZ tools. Further, all three parts are more precisely described and the case studies attached.

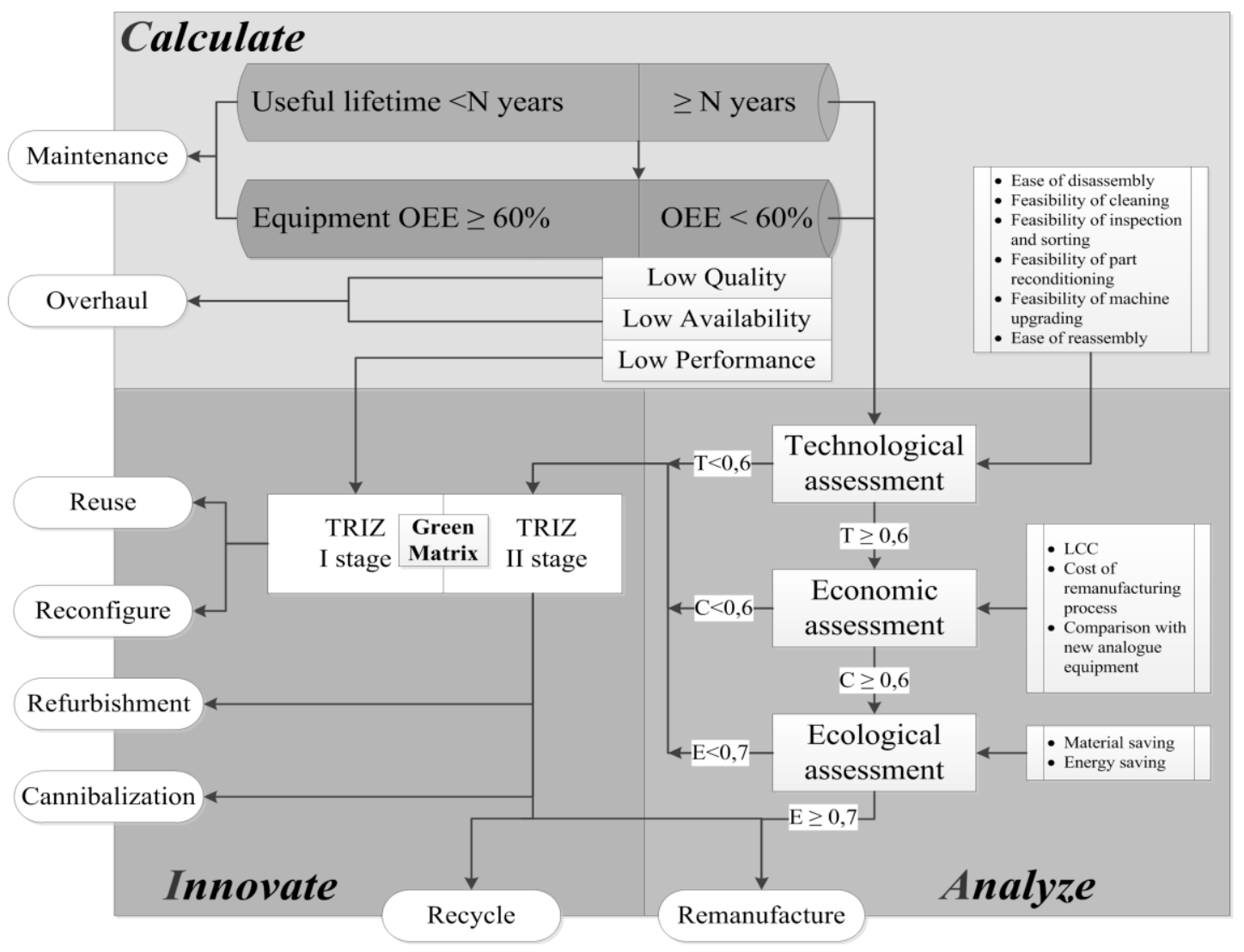

Figure 3. Main decision-making framework for used industrial equipment LCA

\section{Calculate: Definition of Equipment State}

First, the useful estimated life of the spent product is selected for evaluation. Here it should be taken into account that industrial equipment can vary in terms of complexity and the number of assemblies. The age of the used equipment is divided before and after useful life $N$. Relevant numbers can be found in (Table of estimated useful life, www). These numbers can vary from minimum to maximum depending on the exploitation conditions. When the age is defined, the Calculate part is continued with the lean tool - OEE specification (World class OEE).

Overall Equipment Effectiveness, or "OEE," is a wellknown approach how to monitor and manage the life cycles of the different types of machinery. The idea of the concept is in analysis of cumulative metrics what characterizes various aspects of equipment effectiveness. The OEE concept already includes the analysis technique by consistent dipping into the problematic areas, like insignificant organization of equipment workload, low performance or low quality of the manufactured end product.

In general, the OEE indicator is the ratio of fully productive working time (maximum possible production time) to the planned operative time. The effectiveness factors used for this purpose are important in the context of the current research. OEE calculation is presented in (Godfrey, 2002). In the same source is possible to find Top-level OEE and total OEE values from different types of industries: OEE top-level for manufacturing industry is 
$85 \%$, the total OEE rate is $60 \%$ according to overall world practice in manufacturing enterprises.

The OEE performance is a very important factor for second-hand industrial equipment because sometimes the business flow changes and certain machines are used rarely. It is important to have the control over such cases and find another application for infrequently involved equipment in the production process.

When the Calculate stage is finished, the object of study is defined. There are two options considered under the current framework. When OEE $\geq 60 \%$, the used industrial equipment is continuing the cycle of maintenance and waiting for the next assessment period. On the other hand, when OEE $<60 \%$, the object of research is seen through the prism of three OEE main criteria with three possible options.

If the problem is related to Low Quality and/or Low Availability, there is a need to make the proper repairing procedure, like overhaul. If the SME representative faces the Low Performance criteria, it is important to analyze the root of this cause. Sometimes it occurs because the enterprise has changed the direction of business. It is always good to make the situation transparent and try to understand the main causes. The uniqueness of the proposed framework is hidden in the innovation-oriented part. There is a strong need before selling or scrapping the main assets to go through some alternative options by using TRIZ tools. It is important to know that all the options are considered and it is proved; there is no more potential for this specific used machine in this factory. This procedure must involve production specialists, engineers and, certainly, management.

The last choice covers the used equipment that has all three criteria under minimum. It is very important to make clear if it is possible to remanufacture it or not. The "Analyze" part is devoted to definition of the remanufacturing feasibility of the used equipment.

\section{Analyse: Remanufacturing Advisability}

Focus of the Analyze stage is on remanufacturing advisability. It can be analyzed from different perspectives. This research work is dedicated to GM philosophy integration into product end-of-life strategies implementation. That's why the remanufacturability is analyzed from technology, economy and environment point of view.

It is important to mention that the spent industrial equipment may have differences in remanufacturability due to the various service conditions and service times in this stage. That is why it is obligatory to estimate the used product from all aspects. Three indexes are formulated for the decision-making framework. The criteria for technological, economic and environmental assessment are adapted and expanded from the $\mathrm{Du}$, et al., without changing the main indexes. These parameters are presented in Table 2.

There is one significant improvement made for used industrial equipment remanufacturability evaluation and it is in technological assessment - possibility for machine upgrading. Before recycling the expensive cores, the second chance is given to it by implementing different TRIZ tools to prolong its useful life time. If there is no possibility to use "remanufacture", the cores are going to be inspected from TRIZ point of view. There are always options how to prolong the useful lifetime of spent equipment by implementing different end-of-life strategies. Technological assessment

The technological assessment should be estimated in terms of the feasibility of the whole remanufacturing process. The standard remanufacturing process includes disassembly, cleaning, inspection and sorting, part reconditioning, equipment upgrading, and reassembly. The criterion of technological assessment can be calculated using the following equation:

$$
T=\mu_{d} \omega_{d}+\mu_{c} \omega_{c}+\mu_{i} \omega_{i}+\mu_{r} \omega_{r}+\mu_{u} \omega_{u}+\mu_{a} \omega_{a},(1)
$$

Parameter $\mu_{i}$ and $\omega_{i}$ definition is introduced in Table 2. For weight scheme determination for the remanufacturability of used equipment is used method of AHP.

Table 2

The criteria for technological, economic and environmental assessment of used industrial equipment

\begin{tabular}{|c|c|c|c|}
\hline & Index & $\begin{array}{c}\mu, \\
\text { feasibility }\end{array}$ & $\begin{array}{c}\begin{array}{c}w, \\
\text { weight }\end{array}\end{array}$ \\
\hline 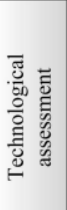 & $\begin{array}{l}\text { Total technological assessment } \mathbf{T} \geq \mathbf{0 . 6} \\
\text { Ease of disassembly } \\
\text { Cleaning assessment } \\
\text { Inspection and sorting evaluation } \\
\text { Assessment of part reconditioning } \\
\text { Possibilities for machine upgrading } \\
\text { Ease of reassembly }\end{array}$ & $\begin{array}{l}\mu d \\
\mu c \\
\mu i \\
\mu r \\
\mu u \\
\mu a\end{array}$ & $\begin{array}{l}\omega d \\
\omega c \\
\omega i \\
\omega r \\
\omega u \\
\omega a\end{array}$ \\
\hline 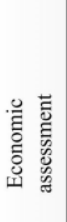 & $\begin{array}{l}\text { Total economic assessment } \mathbf{C} \geq \mathbf{0 . 6} \\
\text { Life Cycle Cost (LCC) } \\
\text { Cost of remanufacturing process } \\
\text { Overhead cost of machine tool remanufacturing } \\
\text { Total cost of equipment remanufacturing } C_{R} \\
\text { Comparison with new analogue equipment } \\
\text { Useful lifetime forecast }\end{array}$ & $\begin{array}{c}C 1 \\
C 2 \\
C 3 \\
\mu e \\
\text { Price } \\
M T B F\end{array}$ & \\
\hline 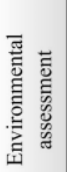 & $\begin{array}{l}\text { Total environmental assessment } \mathbf{E} \geq \mathbf{0 . 7} \\
\text { Material saving } \\
\text { Energy saving } \\
\text { Pollution reduction }\end{array}$ & $\begin{array}{l}\mu m \\
\mu s \\
\mu p\end{array}$ & $\begin{array}{c}\omega m \\
\omega s \\
\omega p\end{array}$ \\
\hline
\end{tabular}

Economic assessment is a part of the "Analyse" stage is modified according to the used industrial equipment singularity. The cores are very expensive and it is not easy to make the decision. The current way seems the most relevant one. Basically, the LCC definition and role in the analysis from the Capital Cost, the Operating Cost and the Cost of Deferred Production is determined $\left(C_{1}\right)$. Then the remanufacturing $\left(C_{2}\right)$ cost is taken into account from the Labour Cost, the Cost of new purchased parts or subassemblies and the Cost of the material consumption perspective.

To finalize the calculations, the overhead cost $\left(C_{3}\right)$ is also viewed, including all possible administrative fees. The main equation looks very simple.

$$
C_{R}=C_{1}+C_{2}+C_{3}
$$

Here the comparison with new analogue equipment is following in two steps: price for new versus remanufactured $\left(C_{R}\right)$ and, naturally, risks evaluation. 
Heinz's calculation method and fuel consumption analysis are considered as the most important in the actual context. According to $\mathrm{Du}, \mathrm{Y}$. if $p$ is the price a consumer is able to pay for the remanufactured product and it is less than $50 \%$ of the same new equipment with the one-to-one performance, the relationship function between $p$ and $C_{R}$ can be found as following.

$$
C_{R}=\mu_{e} \rho,
$$

Heinz's calculation method is needed to forecast the life cycle until the failure of the remanufactured product, demonstrated with the next equation (Bloch, 1998):

$$
\text { MTBF }=\frac{1}{{\frac{1}{L_{1}}}^{2}+{\frac{1}{L_{2}}}^{2}+{\frac{1}{L_{3}}}^{2}+{\frac{1}{L_{4}}}^{2^{0.5}}}
$$

Where $L_{N}$ is the estimated lifetime of the component subject $N$ in years.

The formula requires to have already estimated life cycles until a major repair or service for every subcomponent used, e.g. electric motor, bearing, pump.

Another important issue related to comparison with new analogue industrial equipment is connected to fuel consumption. This must be investigated if a customer is considering using a different type of an engine. For instance, if the equipment was operated by a semi-electric drive and then it will be compared with the electric one. It is obvious that the ROI can be calculated by using the forecast for electricity for the next 5, 10 or 15 years. The same issue can be discussed if there is the opportunity to use the hybrid engine instead of a diesel or a fuel one. This case study does not need any fuel consumption estimation because the truck was diesel and will continue with a diesel engine. The fuel consumption for the new and old truck is approximately the same.

Environmental benefits are investigated differently in order to estimate the environmental impact of used equipment. One possibility is to use the LCA model elaboration for each model year as a function of equipment age. It gives the opportunity to compare the environmental performance between old and remanufactured equipment in the context of scrappage programs. In one research, the dynamic model is developed for the period of time from usage to end-of-life stage for equipment modernization and shown below (Bashkite et al., 2012). As the base of the approach was used Kim, Ross, and Keoleian theory for vehicles LCA assessment (Kim et al., 2004).

Schematic example of the life cycle optimization model based on four policies (see Figure 4) $B 1-B 3$ represent the final environmental burdens for three policies:

a. If the owner keeps the initial equipment throughout the time $N$, the cumulative environmental burden $(B)$ will result in $B 1$.

b. If the owner replaces the initial equipment with a new at time $T a$ and keeps the new equipment until $N$, the cumulative environmental burden $(B)$ will result in $B 2$.

c. If the owner replaces the initial equipment with a new at time $T a$ and replaces this other one again at time $T b$, the cumulative environmental burden $(B)$ will result in $B 3$.

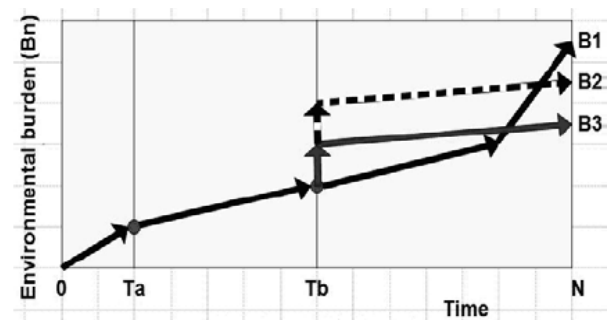

Figure 4. Schematic example of LCA model for environmental burden influence (Bashkite et al., 2012)

In our current research is considered equipment modernization instead of it replacement. In the mathematical model in this case we do not take in account burden of the materials production and manufacturing of equipment. But use new parameter $B_{V}(i, k)$, environmental burden of the modernization. This model helps to put more focus on possible end-of-life strategies analysis from environmental point of view. The equation (5) is presented below.

$$
B=B_{E}(i, k)+\sum_{k=1}^{j}\left(B_{U}(i, k)+B_{R}(i, k)+B_{V}(i, k)\right.
$$

Where:

$B$, cumulative environmental burden;

$B_{V}(i, k)$, environmental burden of the modernization of used equipment;

$B_{U}(i, k)$, burden of the equipment use during years $i, k$ and it service;

$B_{R}(i, k)$, burden of the maintenance during years $i, k$;

$B_{E}(i, k)$, burden of the end-of-life stage of equipment in year $k$.

The Chinese researchers approach for environmental benefits calculation is used in order to keep the simplicity and uniformity of the proposed framework. It can be calculated by Equation (6) (Du et al., 2012):

$$
E=\mu_{m} \omega_{m}+\mu_{s} \omega_{s}+\mu_{\rho} \omega_{\rho}
$$

Only after "Innovative" module implementation the bad cores with low remanufacturability can be recycled. The used industrial equipment is usually a rather complicated product. It is important to utilize all the resources.

\section{Innovate: Using Green Matrix for Solution}

It was one of the major points to combine TRIZ Contradiction Matrix with 40 Principles (Innovative TRIZ, www) with Green Engineering (GE) 12 principles described (Anastas \& Zimmerman, 2003). The aim was to find a fast and relevant way to solve contradictions that would somehow be linked to environmental issues. One possible solution is to integrate GE 12 principles into GM philosophy through the TRIZ Contradiction Matrix. The concept itself was derived during the Lean\&Green Waste Matrix development (Bashkite \& Karaulova, 2012). The goal matches GM direction perfectly. After some investigation GE 12 principles were combined with TRIZ Principles and the TRIZ Matrix was elaborated and presented in Figure 5. 


\begin{tabular}{|c|c|c|c|c|c|c|c|c|c|c|c|c|c|c|c|c|c|c|c|}
\hline Improving & 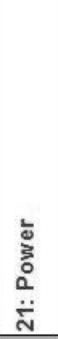 & 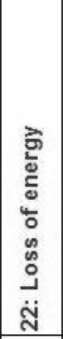 & 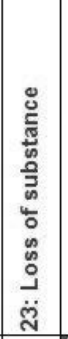 & 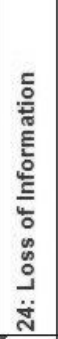 & 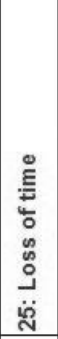 & 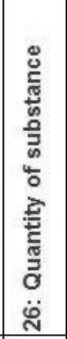 & 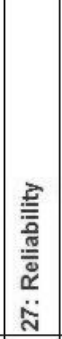 & 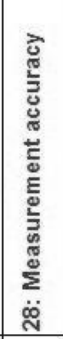 & 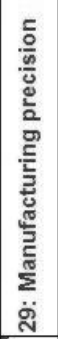 & 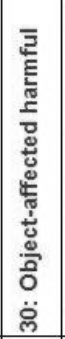 & 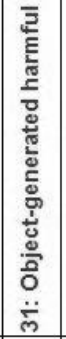 & 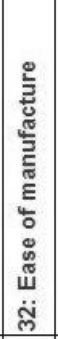 & 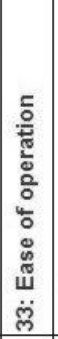 & 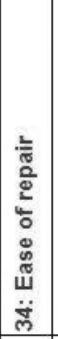 & 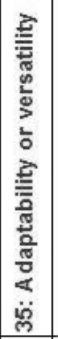 & 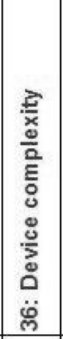 & 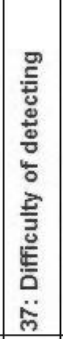 & 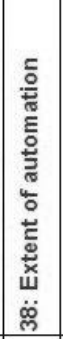 & 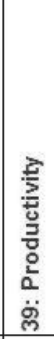 \\
\hline 21: Power & $\mathrm{x}$ & \begin{tabular}{|c|}
10, \\
35,38 \\
\end{tabular} & \begin{tabular}{|l|}
$18,27$. \\
28,38 \\
\end{tabular} & 10,19 & \begin{tabular}{|l|}
6,10, \\
20,35 \\
\end{tabular} & \begin{tabular}{|c}
4.19 \\
34 \\
\end{tabular} & \begin{tabular}{|l|}
19,24, \\
26,31 \\
\end{tabular} & \begin{tabular}{|c}
2,15, \\
22 \\
\end{tabular} & 2,32 & \begin{tabular}{|l|}
2,19 \\
22,31 \\
\end{tabular} & \begin{tabular}{|c|}
2,35, \\
18 \\
\end{tabular} & \begin{tabular}{|c|}
10. \\
26,34 \\
\end{tabular} & \begin{tabular}{|c|}
10, \\
26,35 \\
\end{tabular} & \begin{tabular}{|l|}
2,10, \\
34,35 \\
\end{tabular} & \begin{tabular}{|c|}
17. \\
19,34 \\
\end{tabular} & \begin{tabular}{|c|}
19,20 \\
30,34 \\
\end{tabular} & \begin{tabular}{|c|}
16,19 \\
35 \\
\end{tabular} & \begin{tabular}{|c|}
2,17 \\
28
\end{tabular} & \begin{tabular}{|c}
28,34, \\
35
\end{tabular} \\
\hline 22: $L$ & 38 & $\mathrm{x}$ & \begin{tabular}{|l|}
$2,27$. \\
35,37
\end{tabular} & 10,19 & \begin{tabular}{|l|}
7,10, \\
18,32 \\
\end{tabular} & \begin{tabular}{|c}
$\begin{array}{c}7.18 \\
25\end{array}$ \\
\end{tabular} & $\begin{array}{c}10,11 \\
35\end{array}$ & 32 & - & \begin{tabular}{|l|}
21. \\
.35 \\
\end{tabular} & \begin{tabular}{|l|}
2,21, \\
22,35 \\
\end{tabular} & - & $\begin{array}{c}1,32 \\
35 \\
\end{array}$ & 2,19 & - & 7,23 & \begin{tabular}{|l|}
3,15 \\
23,35 \\
\end{tabular} & 2 & $\begin{array}{l}0,28, \\
29,35 \\
\end{array}$ \\
\hline 23: Lc & & & $\mathrm{x}$ & . & $\begin{array}{r}15 \\
8,35 \\
\end{array}$ & \begin{tabular}{|c|}
$3,6,10$ \\
24 \\
\end{tabular} & $\begin{array}{l}10,29 \\
35,39 \\
\end{array}$ & \begin{tabular}{|l|}
16,28, \\
31,34 \\
\end{tabular} & \begin{tabular}{|l|}
$10,24$. \\
31,35 \\
\end{tabular} & \begin{tabular}{|l|}
$\begin{array}{l}22,30 \\
33,40\end{array}$ \\
\end{tabular} & \begin{tabular}{|l|}
1,10 \\
29,34 \\
\end{tabular} & \begin{tabular}{|c|}
15, \\
33,34 \\
\end{tabular} & \begin{tabular}{|l|}
2,24, \\
28,32 \\
\end{tabular} & \begin{tabular}{|l|}
2,27, \\
34,35 \\
\end{tabular} & $\begin{array}{c}2,10 \\
15 \\
\end{array}$ & \begin{tabular}{|l|}
10,24, \\
28,35 \\
\end{tabular} & \begin{tabular}{|c|}
10,13 \\
18,35 \\
\end{tabular} & \begin{tabular}{|c|}
10,18 \\
35
\end{tabular} & \begin{tabular}{|l|}
$10,23$. \\
28,35 \\
\end{tabular} \\
\hline 24: Loss of Information & 19 & 10,19 & - & $\mathrm{x}$ & \begin{tabular}{|l|}
24,26, \\
28,32 \\
\end{tabular} & $\begin{array}{c}24,28, \\
35\end{array}$ & \begin{tabular}{|c|}
10,23 \\
28
\end{tabular} & - & - & $\begin{array}{c}1,10 \\
22 \\
\end{array}$ & $\begin{array}{c}10,21 \\
22 \\
\end{array}$ & 32 & 22,27 & - & - & - & 33. 35 & 35 & $\begin{array}{c}13,15 . \\
23\end{array}$ \\
\hline 25: L & & & \begin{tabular}{|c|}
10,18 \\
35,39 \\
\end{tabular} & $\begin{array}{l}24,26, \\
28,32 \\
\end{array}$ & $\mathrm{x}$ & $\begin{array}{l}16,18, \\
35,38 \\
\end{array}$ & $\begin{array}{c}4.10 \\
30\end{array}$ & $\begin{array}{l}24,28, \\
32,34 \\
\end{array}$ & & $\begin{array}{c}18,34 . \\
35 \\
\end{array}$ & $\begin{array}{l}18,22, \\
35,39 \\
\end{array}$ & $\begin{array}{l}4,28 \\
34,35 \\
\end{array}$ & \begin{tabular}{|l|}
4 \\
28,10 \\
28,34
\end{tabular} & $\begin{array}{c}1,10 \\
32\end{array}$ & 28,35 & 6. 29 & $\begin{array}{l}10,18 \\
28,32 \\
\end{array}$ & $\begin{array}{l}24,28 \\
30,35 \\
\end{array}$ & \\
\hline 26: Quantity of substance/the & 35 & $\begin{array}{c}7,18 \\
25\end{array}$ & \begin{tabular}{|c|}
3,6 \\
10,24 \\
\end{tabular} & \begin{tabular}{|c}
24,28, \\
35 \\
\end{tabular} & & $\mathrm{x}$ & \begin{tabular}{|l|}
3,18 \\
28,40 \\
\end{tabular} & $\begin{array}{c}2,13 \\
28\end{array}$ & 30,33 & \begin{tabular}{|c|}
29,31 \\
33,35 \\
\end{tabular} & \begin{tabular}{|l|}
3,35 \\
39,40 \\
\end{tabular} & $\begin{array}{l}1,27 \\
29,35 \\
\end{array}$ & \begin{tabular}{|c|c}
10 \\
25 \\
29 & 35 \\
\end{tabular} & \begin{tabular}{|l|}
2,10, \\
25,32 \\
\end{tabular} & \begin{tabular}{|c|}
3,15 \\
29 \\
\end{tabular} & \begin{tabular}{|l|}
3,10 \\
13,27 \\
\end{tabular} & \begin{tabular}{|l|}
3,18, \\
27,29 \\
\end{tabular} & 8. 35 & $\begin{array}{l}3,13, \\
27,29 \\
\end{array}$ \\
\hline 27: $\operatorname{Re}$ & & $\begin{array}{c}10,11 \\
35 \\
\end{array}$ & \begin{tabular}{|c|}
10,29, \\
35,39 \\
\end{tabular} & 10,28 & $\begin{array}{c}4,10 \\
30 \\
\end{array}$ & & $\mathrm{x}$ & $\begin{array}{l}\begin{array}{l}3,11 \\
23,32\end{array} \\
\end{array}$ & $\begin{array}{c}1,11 \\
32 \\
\end{array}$ & \begin{tabular}{|l|}
2,27 \\
35,40 \\
\end{tabular} & \begin{tabular}{|l|}
2,26, \\
35,40 \\
\end{tabular} & - & \begin{tabular}{|c|}
17. \\
27,40 \\
\end{tabular} & 1,11 & \begin{tabular}{|l|}
8,13 \\
24,35 \\
\end{tabular} & \begin{tabular}{|c|}
1,13 \\
35 \\
\end{tabular} & \begin{tabular}{|c|}
27,28 \\
40 \\
\end{tabular} & \begin{tabular}{|c|}
11,13 \\
27
\end{tabular} & $\begin{array}{l}1,29, \\
35,38 \\
\end{array}$ \\
\hline 28: Mea & 6,32 & \begin{tabular}{|c|}
26,27 \\
32 \\
\end{tabular} & \begin{tabular}{|l|}
10,16, \\
28,31 \\
\end{tabular} & - & \begin{tabular}{|l}
24,28, \\
32,34 \\
\end{tabular} & $2,6,32$ & & $\mathrm{x}$ & - & & \begin{tabular}{|l|}
3,10 \\
33,39 \\
\end{tabular} & \begin{tabular}{|l|}
6,18, \\
25,35 \\
\end{tabular} & \begin{tabular}{|l|}
1,13 \\
17,34 \\
\end{tabular} & \begin{tabular}{|l|}
1,11, \\
13,32 \\
\end{tabular} & \begin{tabular}{|c|}
2,13 \\
35 \\
\end{tabular} & \begin{tabular}{|c|}
10,27, \\
34,35 \\
\end{tabular} & \begin{tabular}{|l|}
24,26, \\
28,32 \\
\end{tabular} & \begin{tabular}{|l|}
2,10 \\
28,34 \\
\end{tabular} & \begin{tabular}{|l}
10,28, \\
32,34 \\
\end{tabular} \\
\hline 29: Manufacturing & 32 & $\begin{array}{c}2,13 \\
32 \\
\end{array}$ & \begin{tabular}{|}
10,24, \\
31,35 \\
\end{tabular} & - & & 30,32 & $\begin{array}{c}1,11 \\
32\end{array}$ & - & $\mathrm{x}$ & $\begin{array}{c}10,26 \\
28,36 \\
\end{array}$ & $\begin{array}{l}4,17 \\
26,34 \\
\end{array}$ & - & 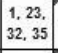 & 10,25 & - & \begin{tabular}{|c|}
2,18 \\
26
\end{tabular} & . & $\begin{array}{l}3 . \\
28 \\
\end{array}$ & $\begin{array}{l}10,18 \\
32,39 \\
\end{array}$ \\
\hline 30: Obj & & \begin{tabular}{|l|}
2,21, \\
22,35 \\
\end{tabular} & \begin{tabular}{|l|}
19,22, \\
33,40 \\
\end{tabular} & $\begin{array}{c}2,10 \\
22\end{array}$ & $\begin{array}{c}18,34 . \\
35\end{array}$ & \begin{tabular}{|l|}
29,31 \\
33,35 \\
\end{tabular} & \begin{tabular}{|l|}
2,24 \\
27,40 \\
\end{tabular} & \begin{tabular}{|l}
$23,26$. \\
28,33 \\
\end{tabular} & \begin{tabular}{|l}
10,18, \\
26,28 \\
\end{tabular} & $\mathrm{x}$ & - & \begin{tabular}{|c|}
2,24 \\
35
\end{tabular} & \begin{tabular}{|l|}
2,25, \\
28,39 \\
\end{tabular} & \begin{tabular}{|c|}
2,10 \\
35 \\
\end{tabular} & \begin{tabular}{|c|}
11 \\
22. \\
31 \\
31
\end{tabular} & \begin{tabular}{|l|}
19,22, \\
29,40 \\
\end{tabular} & \begin{tabular}{|l|}
19,22, \\
29,40 \\
\end{tabular} & \begin{tabular}{|c|}
3,33 \\
34
\end{tabular} & \begin{tabular}{|l|}
13,22, \\
24,35 \\
\end{tabular} \\
\hline 31: Object- & $\begin{array}{c}2,18 \\
35\end{array}$ & \begin{tabular}{|l|}
2,21, \\
22,35 \\
\end{tabular} & \begin{tabular}{|c|}
1,10 \\
34 \\
\end{tabular} & $\begin{array}{c}10,21, \\
29 \\
\end{array}$ & 1,22 & $\begin{array}{c}1,3,24 . \\
39\end{array}$ & \begin{tabular}{|l|}
2,24 \\
39,40 \\
\end{tabular} & $\begin{array}{c}\text { 3. } 26, \\
33\end{array}$ & & . & $\mathrm{x}$ & - & - & & . & \begin{tabular}{|c|}
1.19 \\
31 \\
\end{tabular} & \begin{tabular}{|c|}
$1,2$. \\
21,27 \\
\end{tabular} & 2 & \begin{tabular}{|l|}
18.22, \\
35,39 \\
\end{tabular} \\
\hline 32: Eas & & 19. 35 & \begin{tabular}{|c|}
$5,33$. \\
34
\end{tabular} & $\begin{array}{r}16,18, \\
24,32 \\
\end{array}$ & & & - & 5 & - & 24 & - & $\mathrm{x}$ & \begin{tabular}{|c|}
2,5 \\
13,16 \\
\end{tabular} & \begin{tabular}{|c|}
1,9 \\
11,35 \\
\end{tabular} & \begin{tabular}{|c|}
2,13 \\
15
\end{tabular} & \begin{tabular}{|c|}
1,26 \\
27 \\
\end{tabular} & \begin{tabular}{|c|}
1,6 \\
11,28 \\
\end{tabular} & $\begin{array}{c}1,8 \\
28 \\
\end{array}$ & \begin{tabular}{|l}
1,10, \\
28,35 \\
\end{tabular} \\
\hline 33: Ea & & \begin{tabular}{|c|}
2,13 \\
19 \\
\end{tabular} & \begin{tabular}{|l|}
2,24, \\
28,32 \\
\end{tabular} & $\begin{array}{l}4,10, \\
22,27 \\
\end{array}$ & \begin{tabular}{|l|}
4,10 \\
28,34 \\
\end{tabular} & 35 & \begin{tabular}{|l|}
8,17 \\
27,40 \\
\end{tabular} & $\begin{array}{r}2,13 \\
25,34 \\
\end{array}$ & $\begin{array}{l}1,23 \\
32,35 \\
\end{array}$ & \begin{tabular}{|l|}
2,25 \\
28,39 \\
\end{tabular} & - & $\begin{array}{c}2,5 \\
12 \\
\end{array}$ & $\mathrm{x}$ & $\begin{array}{c}1,12, \\
26,32 \\
\end{array}$ & \begin{tabular}{|c|}
1,15 \\
16,34 \\
\end{tabular} & \begin{tabular}{|c|}
12,17 \\
26,32 \\
\end{tabular} & - & \begin{tabular}{|c|}
1,3 \\
12,34 \\
\end{tabular} & $\begin{array}{c}1,15, \\
28\end{array}$ \\
\hline 34: Ease & & \begin{tabular}{|l|}
1,15 \\
19,32 \\
\end{tabular} & \begin{tabular}{|l|}
2,27, \\
34,35 \\
\end{tabular} & - & & & & $\begin{array}{c}2,10 \\
13 \\
\end{array}$ & 10.25 & & . & \begin{tabular}{|l|}
$1,10$. \\
11,35 \\
\end{tabular} & \begin{tabular}{|l|}
1,12 \\
15,26 \\
\end{tabular} & $\mathrm{x}$ & \begin{tabular}{|l|}
1,4 \\
7,16 \\
\end{tabular} & & & & $\begin{array}{c}1,10 . \\
32\end{array}$ \\
\hline 35: A & $\begin{array}{c}1,19 \\
29 \\
\end{array}$ & \begin{tabular}{|c}
1,15 \\
18 \\
\end{tabular} & \begin{tabular}{|l|}
2,10, \\
13,15 \\
\end{tabular} & - & .35 & \begin{tabular}{|c|}
3,15 \\
35 \\
\end{tabular} & \begin{tabular}{|l|}
8,13, \\
24,35 \\
\end{tabular} & $\begin{array}{c}1.5 \\
10.35 \\
\end{array}$ & & $\begin{array}{l}11,31 \\
32,35 \\
\end{array}$ & . & $\begin{array}{c}1,13 \\
31 \\
\end{array}$ & \begin{tabular}{|l|}
1,15 \\
16,34 \\
\end{tabular} & \begin{tabular}{|l|}
1,4 \\
7,16 \\
\end{tabular} & 15 & \begin{tabular}{|l|}
15,28, \\
29,37 \\
\end{tabular} & 1 & \begin{tabular}{|c|}
27.34 \\
35
\end{tabular} & \begin{tabular}{|l}
6,28, \\
35,37 \\
\end{tabular} \\
\hline 36: [ & & \begin{tabular}{|l|}
2,10 \\
13,35 \\
\end{tabular} & \begin{tabular}{|c|}
10,28, \\
29,35 \\
\end{tabular} & - & 29 & & $\begin{array}{c}1,13, \\
35 \\
\end{array}$ & \begin{tabular}{|l}
2,10 \\
26,34 \\
\end{tabular} & \begin{tabular}{|c}
24,26, \\
32 \\
\end{tabular} & $\begin{array}{c}19,22, \\
29,40 \\
\end{array}$ & 1. 19 & \begin{tabular}{|l|}
1,13 \\
26,27 \\
\end{tabular} & \begin{tabular}{|l|}
9,24, \\
26,27 \\
\end{tabular} & 1,13 & $\begin{array}{c}15, \\
28, \\
29.37 \\
2\end{array}$ & $\mathrm{x}$ & $\begin{array}{r}0.15 \\
8.37 \\
\end{array}$ & $\begin{array}{c}1,15 \\
24 \\
\end{array}$ & \begin{tabular}{|c}
$12,17$. \\
28
\end{tabular} \\
\hline 37: Diffic & $\begin{array}{l}10, \\
18 \\
\end{array}$ & \begin{tabular}{|l}
3,15 \\
19,35 \\
\end{tabular} & \begin{tabular}{|l|}
1,10 \\
18,24 \\
\end{tabular} & $\begin{array}{l}22,27 \\
33,35 \\
\end{array}$ & \begin{tabular}{|l}
9,18, \\
28,32 \\
\end{tabular} & & $\begin{array}{l}8,27 . \\
28,40 \\
\end{array}$ & \begin{tabular}{|l}
24,26, \\
28,32 \\
\end{tabular} & - & & 2,21 & \begin{tabular}{|l|}
5,11 \\
28,29 \\
\end{tabular} & 2,5 & 12,26 & 1,15 & $\begin{array}{l}10,15 \\
28,37 \\
\end{array}$ & $\mathrm{x}$ & 21,34 & 18, 35 \\
\hline n & $\begin{array}{c}2.27 . \\
28\end{array}$ & 28 & \begin{tabular}{|l|}
5,10, \\
18,35 \\
\end{tabular} & 33,35 & \begin{tabular}{|l}
24,28, \\
30,35 \\
\end{tabular} & 13,35 & \begin{tabular}{|c|}
11.27. \\
32 \\
\end{tabular} & \begin{tabular}{|l}
10,26, \\
28,34 \\
\end{tabular} & & 3 & 2 & $\begin{array}{c}1,13 \\
26\end{array}$ & \begin{tabular}{|c|}
1,3 \\
12,34 \\
\end{tabular} & \begin{tabular}{|c|}
1.13 \\
35 \\
\end{tabular} & \begin{tabular}{|c|}
1,4 \\
27,35 \\
\end{tabular} & \begin{tabular}{|c|}
10,15, \\
24 \\
\end{tabular} & \begin{tabular}{|c|}
25.27 \\
34 \\
\end{tabular} & $\mathrm{x}$ & \begin{tabular}{|l|}
5,12, \\
26,35 \\
\end{tabular} \\
\hline 39: $\mathrm{Pr}$ & $\begin{array}{c}10,20 . \\
35\end{array}$ & \begin{tabular}{|l|}
10,28, \\
29,35 \\
\end{tabular} & \begin{tabular}{|c|}
10,23, \\
28,35
\end{tabular} & $\begin{array}{c}13,15 \\
23\end{array}$ & - & 58 & $\begin{array}{l}1,10 \\
35,38\end{array}$ & 28,34 & \begin{tabular}{|l}
1,10 \\
18,32
\end{tabular} & $\begin{array}{l}13,22, \\
24,35\end{array}$ & \begin{tabular}{|l|}
18,22 \\
35,39
\end{tabular} & $\begin{array}{l}2,24 . \\
28,35\end{array}$ & $\begin{array}{c}1,7 \\
10,28 \\
\end{array}$ & $\begin{array}{l}1,10 \\
25,32\end{array} \mid$ & $\begin{array}{l}1,28, \\
35,37\end{array} \mid$ & \begin{tabular}{|l|}
$12,17$. \\
24,28
\end{tabular} & \begin{tabular}{|l|}
2,18, \\
27,35
\end{tabular} & $\begin{array}{ll}0,32, \\
26,35\end{array}$ & $\mathrm{x}$ \\
\hline
\end{tabular}

Figure 5. TRIZ Matrix for Green Manufacturing

\section{Case Study 1}

The object for study is a used lorry truck with a grab crane and high mileage. The truck had the following technical specifications:

- Weight $-26 \mathrm{t}$;

- Manufacturer - IVECO;

- Year of manufacturing - 2001;

- Condition - content;

- Estimated value - 23,800.00 EUR;

- Comment - the lorry was used to load and transport free-flowing soil.

The useful lifetime of such machines is eight years. The current state of the OEE was less than $60 \%$. The truck was in the working condition, but last year the OEE dropped to $56 \%$. It was necessary to handle the query for remanufacturability by using the second stage of the proposed framework "Analyze".

It is important to mention that the spent industrial equipment may have differences in remanufacturability due to the various service conditions and service times in this stage. That is why it is obligatory to estimate the used product from all aspects. Three main assessment parameters are presented in Table 3.

The estimated lifetime for the IVECO lorry with minor repairs is $N_{l}=5$ years. An estimated lifetime for EB50 also with minor repairs, appropriate care and full working load is $N_{2}=10$ years. An estimated lifetime before failure for electric motors used in this mixing plant is considered $N_{3}=$ 4 years. A summary MTBF will be three years. Thus, it is crucial to supply a customer with appropriate technical help and maintenance to avoid earlier failures happening. It is important to mention that during this estimation mixer blades were not considered even though they are the fastest wearing-out parts. They are replaced according to specific requirements, considering how frequently a mixer is used and what sort of spoil or rubble is mixed.

The lorry has a high mileage, meaning that it has spent almost $3 / 4$ of its resource as a truck. The ideal final result for this lorry (see Table 3 ) is not to travel, but the condition is still too good for disposal. The remanufacturability analysis has proved that this lorry can be remanufactured from every aspect. 
Experimental results of the used lorry case study

\begin{tabular}{|c|c|c|c|c|c|}
\hline Criteria & Index & \multicolumn{2}{|c|}{$\mu$, feasibility } & \multicolumn{2}{|r|}{$\omega$, weight } \\
\hline \multirow{7}{*}{ Technological assessment } & Ease of disassembly & $\mu_{d}$ & 0.6 & $\omega_{d}$ & 0.266 \\
\hline & Feasibility of cleaning & $\mu_{c}$ & 0.55 & $\omega_{c}$ & 0.048 \\
\hline & Feasibility of inspection and sorting & $\mu_{i}$ & 0.8 & $\omega_{i}$ & 0.048 \\
\hline & Feasibility of part reconditioning & $\mu_{r}$ & 0.5 & $\omega_{r}$ & 0.265 \\
\hline & Feasibility of machine upgrading & $\mu_{u}$ & 0.8 & $\omega_{u}$ & 0.265 \\
\hline & Ease of reassembly & $\mu_{a}$ & 0.7 & $\omega_{a}$ & 0.108 \\
\hline & \multicolumn{5}{|l|}{ Total technological assessment $T=0.6445$} \\
\hline \multirow{7}{*}{ Economic assessment } & Life Cycle Cost (LCC) & $C_{l}$ & \multicolumn{2}{|l|}{$23800 €$} & \\
\hline & Cost of remanufacturing process & $C_{2}$ & \multicolumn{2}{|l|}{$5000 €$} & \\
\hline & Overhead cost of machine tool remanufacturing & $C_{3}$ & \multicolumn{2}{|l|}{$8980 €$} & \\
\hline & Total cost of equipment remanufacturing $C_{R}$ & $\mu_{e}$ & \multicolumn{2}{|l|}{0.4} & \\
\hline & Comparison with new analogue equipment & Price & \multicolumn{2}{|c|}{$33980 €$ versus $88900 €$} & Less than $50 \%$ \\
\hline & Useful lifetime forecast & $M T B F$ & \multicolumn{2}{|l|}{3 years } & Warranty is 2 years \\
\hline & \multicolumn{5}{|l|}{ Total economic assessment $C=1$} \\
\hline \multirow{4}{*}{ Environmental assessment } & Material saving & $\mu_{m}$ & 1 & $\omega_{m}$ & 0.5 \\
\hline & Energy saving & $\mu_{s}$ & 1 & $\omega_{s}$ & 0.3 \\
\hline & Pollution reduction & $\mu_{p}$ & 0.95 & $\omega_{p}$ & 0.3 \\
\hline & \multicolumn{5}{|l|}{ Total environmental assessment $E=1$} \\
\hline
\end{tabular}

\section{Case Study 2}

Using TRIZ Matrix for Green Manufacturing can be shown on the example one Estonian machinery company. Company has different types of machines, but mostly and commonly used are lathes and milling machines. Machinery useful life cycle is 15-20 years. Of course, the oldest equipment is already remanufactured many times and has almost all new components. The average age for lathes is 26 years and 33 years for the milling machines respectively. The overall tendency is seen in Table 4.

Table 4

\section{Repairing cost of equipment}

\begin{tabular}{|l|c|c|c|c|c|c|}
\hline \multicolumn{4}{|c|}{ Average repairing cost of a machine tool $(\epsilon)$} \\
\hline & \multicolumn{3}{|c|}{$\begin{array}{c}\text { First period } \\
2007-2009\end{array}$} & \multicolumn{3}{c|}{$\begin{array}{c}\text { Second period } \\
\text { 2010-2012 }\end{array}$} \\
\hline & 2007 & 2008 & 2009 & 2010 & 2011 & 2012 \\
\hline Lather machine & 2980 & 3015 & 3030 & 3080 & 3140 & 3190 \\
\hline $\begin{array}{l}\text { Total cost during } \\
\text { period }\end{array}$ & \multicolumn{3}{|c|}{9025} & \multicolumn{3}{c|}{9410} \\
\hline Milling machine & 3350 & 3400 & 3410 & 3460 & 3530 & 3580 \\
\hline $\begin{array}{l}\text { Total cost during } \\
\text { period }\end{array}$ & \multicolumn{5}{|c|}{10160} & \multicolumn{3}{c|}{10570} \\
\hline
\end{tabular}

Since 2007 the downtime recurrence and time spent on repairs is just growing. In 6 years it is almost doubled for both types of machines.

The biggest fault for lathes is setup. The milling machines are suffering mostly from electric faults and the second one is again setup. In the section of decision searching process, the main focus is on setup fault by solving defined technical contradiction between improving factors "ease of operation" and worsening "adaptability or versatility". The solution can help to prolong useful life span of lathes and milling machines. It will be the alternative option what can be also taken into account during decision making procedure or somehow combined with the main proposal. According to developed TRIZ Matrix for Green Manufacturing (in Figure 5, at intersection of fields "Easy of operation" and "Adaptability or versatility") the following technical contradiction can be solved by using 4 different principles of TRIZ. Matrix is giving principles: 15, 34, 1 and 16 shown in Figure 6. More precise description of this case study for used equipment analysis are introduced in Bashkite, paper "Framework for Innovation-Oriented Product End-of-Life Strategies Development" (Bashkite et al., 2013).

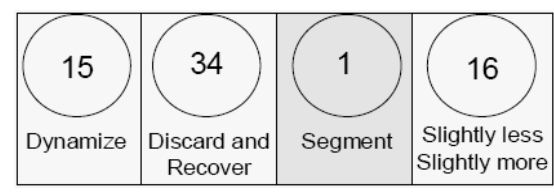

Figure 6. Solution for "setup" fault by using TRIZ Matrix

This time all options can be used and explained. The third option "Segment" looks good due to it is not showing direction to EOL strategies, such as 3R (reduce/reuse/ recycle). For example, next possible extra options can be added to general decision, such as the manufacturing process can be divided (separated) among different machines. This will reduces the number of operations for one machine. In addition machines will be used less and the problematic spare parts will have less stress during setups. Another option is to group machines according to their specification and technical problems and tries to separate products according to that in order to keep the quality level and decrease the number of setups. The possible end-of-life strategies were chosen in order to maximum utilizes the existing equipment and minimizes the environmental impact and new resource consumption.

\section{Conclusion}

The approach for life cycle extension of existing industrial equipment was developed to show how it can be integrated under one mechanism. The idea was to create a well-ordered approach for the state analysis of the used industrial equipment and simplify SME decision-making for finding more suitable solution for its utilization. 
In the decision-making framework for assessing the condition of the equipment, much attention was paid to the remanufacturing process. An integrated method for evaluating the remanufacturability of the used industrial equipment is proposed, in which the technological, economic and environmental assessment of the spent machinery remanufacturing is analyzed.

The combination of Lean fundamentals with TRIZ tools and GE principles resulted in the new Lean\&Green Waste Matrix for various solution evaluations and the Green Matrix for environmental contradiction solving was used in current research. It must help enterprises and entrepreneurs to improve the efficiency of utilized resources and up value environmental issues by prolonging used machinery life cycle.

The new innovation-oriented approach for the life cycle extension and control of the used industrial equipment is based on the assumption that resource conservation is a major direction of GM development, which is directed by laws for environment protection all over the world and principles of GE through innovationoriented TRIZ. The maximum utilization of existing industrial equipment resources in the EOL stage helps enterprises to save money and time.

\section{Acknowledgement}

This research was supported by Estonian Ministry of Education and Research for targeted financing scheme B41.

\section{References}

AME (2007). Association for Manufacturing Excellence, Green manufacturing: case studies in lean and sustainability, Productivity Press (material originally appeared in Target), New York, ISBN 978-1-56327-389-6.

Anastas, P., \& Zimmerman, J. (2003). Gesign through of 12 Principles of Green Engineering, Environmental Science \& Technology, Available in internet: http://pubs.acs.org/doi/pdf/10.1021/es032373g

Bashkite, V., Durmanenko, D., \& Karaulova, T. (2012). Life Cycle Extension for Used Vehicles and Their Environmental Impact. Proceedings of the 8th International Conference on DAAAM Baltic Industrial Engineering, TUT Press, 401406.

Bashkite, V., \& Karaulova, T. (2012). Integration of Green thinking into Lean fundamentals by Theory of Inventive Problems-Solving tools. Proceedings of DAAAM International, Vienna, Austria, EU, Ed. B. Katalinic, 345-350.

Bashkite, V., Karaulova, T., \& Starodubtseva, O. (2013). Framework for Innovation-Oriented Product End-of-Life Strategies Development. Procedia Engineering: 24th DAAAM International Symposium on Intelligent Manufacturing and Automation, Ed. Katalinic, B. Elsevier.

Bloch, H. P. (1998). Improving Machinery Reliability, Practical Machinery Management for Process Plants, $3^{\text {rd }}$ ed., Vol.1, 250-290

Bryant, J. E., Pead, E. F., \& Spiller, J. V. (2005). Elements of Mechanical Equipment life-cycle cost analysis, Proceedings of the $30^{\text {th }}$ Turbomachinery Symposium, 177-182.

Cheng Wu. (2007). Handbook of Industrial Engineering: Technology and Operation Management, Wiley-Interscience Publication John Wiley \& Sons, Inc., New York, $3^{\text {rd }}$ Edition.

Cohen, M. (1988). Replace, rebuild or remanufacture. Equipment Management, 16(1), 22-26.

Du, Y., Cao, H., Liu, F., Li, C., \& Chen, X. (2012). An integrated method for evaluating the remanufacturability of used machine tool. Journal of Cleaner Production, 20(1), 82-91. http://dx.doi.org/10.1016/j.jclepro.2011.08.016

EC (2013) European Commission. The EU Framework Programme for Research and Innovation. Project: "Horizon 2020”. Available in the internet: http://ec.europa.eu/research/horizon2020/index_en.cfm?pg=h2020

Godfrey, P. (2002). Overall equipment effectiveness. Manufacturing Engineer, 81(3), 109-112. http://dx.doi.org/10. 1049/me:20020302

Karaulova, T., Kostina, M., \& Shevtshenko, E. (2012). Reliability Assessment of Manufacturing Processes.

International Journal of Industrial Engineering and Management, No 3, 143-151. Available in the internet: http://www.iim.ftn.uns.ac.rs/casopis/volume3/ijiem_vol3_no3_3.pdf

Kim, H. C., Ross, M. H., \& Keoleian, G. A. (2004). Optimal fleet conversion policy from a life cycle perspective, Elsevier, Transportation Research, Part D 9 229-249. http://dx.doi.org/10.1016/j.trd.2004.02.004

Lansink, M. (1980). Vergaderjaar 1979-1980, Nr. 21, 15-800. Kamer, T., adopted figure from WASTEWATCH, FRIENDS OF THE EARTH and UK WASTE, Beyond the bin: the economics of waste management options, Waste online, http://www.wasteonline.org.uk/resources/WasteWatch/BeyondTheBin_files/page8.html

Legendre, P. (2010). Coefficient of concordance. Encyclopedia of Research Design. SAGE Publications. 2010. http://dx.doi.org/10.4135/9781412961288.n55

Lund, R. (1984). Remanufacturing: the Experience of the United States and Implications for Developing Countries. World Bank, Washington DC.

Loun, K., Lavin, J., Riives, J., \& Otto, T. (2013). High performance workplace design model. Estonian Journal of Engineering, 19(1), 47-61. http://dx.doi.org/10.3176/eng.2013.1.05 
Moseichuk, V., Bashkite, V., \& Karaulova, T. (2010). Lifecycle extension for industrial equipment. Proceedings of 7th International Conference of DAAAM Baltic Industrial Engineering, 364-369.

Peter Paul Electronics (2013). Lean Manufaturing, Available from: http://peterpaul.com/capabilities/lean-manufacturing/

Ravipudi, V. R., \& Padmanabhan, K. K. (2010). Selection of best product end-of-life scenario using digraph and matrix methods. Journal of Engineering Design, 21(4), 455-472. http://dx.doi.org/10.1080/09544820802406129

Saaty, T. L. (2008). Decision making with the analytic hierarchy process. International Journal of Service Sciences, 1(1), 83-98. Available in the internet: http://www.colorado.edu/geography/leyk/geog_5113/readings/ saaty_2008.pdf http://dx.doi.org/10.1504/IJSSCI.2008.017590

Saavedra, Y. M. B., Barquet, A. P. B., Rozenfeld, H., Forcellini, F. A., \& Ometto, A. R. (2013). Remanufacturing in Brazil: case studies on the automotive sector. Journal of Cleaner Production, 53, 267-276. http://dx.doi.org/10. 1016/j.jclepro.2013.03.038

Shevtshenko, E., Bashkite, V., Maleki, M., \& Wang, Y. (2012). Sustainable Design of Material Handling Equipment: A win-win approach for manufacturers and customers. Mechanika, 18(5), 561-568. http://dx.doi.org/10.5755/j01. mech.18.5.2703

Standard, N. (1996). Life cycle cost for systems and equipment. Table-of-Estimated-Useful-Lives Available: http://www.docstoc.com/docs/68215370/Annex-7---T

Toensmeier, P. A. (1992). Remanufacture does more than just save on investment. Modern Plastics, 69(4), 77-79.

Tahemaa, T., Temberbulatova, A., \& Karjust, K. (2012). Lean production development in Estonian SME's. Proceedings of the 8th International Conference of DAAAM Baltic Industrial Engineering, Tallinn, 603-608.

Wilder, R. V. (1988) Remanufacturing: Upgrading can be better than buying new. Modern Plastics, 65(4), 73-77.

World class OEE. Available in the internet: htpp://www.oee.com/world-class-oee.html

Zahharov, R., Bashkite, V., Karaulova, T., \& Miina, A. (2011). Industrial building life cycle extension through concept of modular construction. Proceedings of the 21st DAAAM World Symposium, 805-806.

The article has been reviewed.

Received in November 2014; accepted in February, 2016. 